\title{
INTEGRATING THE TAILS OF TWO MACLAURIN SERIES
}

\author{
Russell A. GORDON
}

\begin{abstract}
The values of four improper integrals containing the squares of the tails of the Maclaurin series for the sine and cosine functions are computed using standard residue theory for contour integrals. Using a very different approach, we then provide solutions to some open questions concerning two related improper integrals.
\end{abstract}

Mathematics subject classification (2020): 33B10, 40A10, 30B10.

Keywords and phrases: Residue theory, improper integrals, Maclaurin series, harmonic numbers.

\section{REFERENCES}

[1] G. J. O. Jameson, Sine, cosine and exponential integrals, Math. Gaz., 99, (2015), 276-289.

[2] E. SAFF AND A. Snider Fundamentals of Complex Analysis, 3rd edition, Pearson Education, Inc. 2003.

[3] S. M. STEWART Some improper integrals involving the square of the tail of the sine and cosine functions, J. Class. Anal. 16 (2020), no. 2, 91-99. 